\title{
PENGARUH BIMBINGAN KELOMPOK DENGAN TEKNIK SOSIODRAMA TERHADAP KONTROL DIRI
}

\author{
Alga Bisma Nugraha', G. Rohastono Ajie $^{2}$ \\ 1,2, Program Studi Bimbingan dan Konseling, Fakultas IImu Pendidikan, \\ Universitas PGRI Semarang \\ e-mail: algabisma1526@gmail.com
}

\begin{abstract}
ABSTRAK
Penelitian ini bertujuan untuk mengetahui pengaruh layanan bimbingan kelompok dengan teknik sosiodrama terhadap kontrol diri siswa. Jenis penelitian ini adalah penelitian kuantitatif melalui metode penelitian true experimental design dengan model pre-test post-test control group design. Populasi dalam penelitian ini adalah 69 siswa. Sampel dalam penelitian yaitu 20 siswa kelas X SMK Nusa Bangsa Demak yang diambil dengan menggunakan teknik simple random sampling. Alat pengumpul data yang dipergunakan adalah skala kontrol diri. Berdasarkan hasil analisis uji hipotesis diperoleh hasil thitung $=3,62$. Selanjutnya dikonsultasikan dengan ttabel dengan taraf signifikansi $5 \%$ (0.05) yaitu 2,100. Hal tersebut menunjukkan bahwa thitung $=3,62>$ ttabel $=2,100$. Atas dasar perhitungan tersebut maka hipotesis alternatif $(\mathrm{Ha})$ yang berbunyi "ada pengaruh layanan bimbingan kelompok dengan teknik sosiodrama terhadap kontrol diri diri siswa kelas X SMK Nusa Bangsa Demak tahun pelajaran 2019/2020" diterima kebenarannya pada taraf signifikansi 5\%. Dengan demikian menunjukkan bahwa layanan bimbingan kelompok dengan teknik sosiodrama dapat meningkatkan kontrol diri siswa.
\end{abstract}

Kata Kunci : Bimbingan Kelompok, Teknik Sosiodrama, Kontrol Diri

\begin{abstract}
This study discusses group guidance with sociodrama techniques on student self control. This type of research is quantitative research through true experimental design research methods with the model pre-test post-test control group design. The population in this study was 69 students. The sample in this study was 20 grade $X$ students of SMK Nusa Bangsa Demak taken using simple random sampling technique. The data collection tool used is a self-control scale. Based on the results of the analysis, the hypothesis obtained, $t=3.62$. Furthermore, it is consulted with a table with a significance level of $5 \%(0.05)$, namely 2,100. This shows that tcount $=3.62>t$ table $=2.100$. On the basis of these calculations, the alternative hypothesis $(\mathrm{Ha})$ which reads "there is a comparison of guidance services with sociodrama techniques to self-control of class $X$ students of SMK Nusa Bangsa Demak 2019/2020 school year" asks for truth at a 5\% significance level. Thus showing that group guidance services with sociodrama can improve student self control.
\end{abstract}

Keywords : Group Guidance, Sociodrama Technique, Self Control. 


\section{Pendahuluan}

Sekolah merupakan lembaga pendidikan formal yang di dalamnya terdapat aktivitas guru dalam mengajar, mendidik, membimbing, dan melatih serta memperbaiki perilaku siswa. Dalam kenyataan sehari-hari dijumpai dari sekian banyak peserta didik yang memiliki kontrol diri rendah. Rendahnya kontrol diri merupakan masalah yang sering dialami oleh anak usia remaja.

Masa remaja merupakan salah satu fase dalam kehidupan yang dapat ditandai dengan perkembangan fisik maupun psikis, usia remaja smk terkisar antara $15-18$ (Fatimah, 2010:108). Peralihan masa remaja menuju dewasa awal menjadi sebuah rintangan yang harus dilalui oleh setiap remaja, contohnya adalah pembentukan jatidiri. Pergaulan remaja tidak dapat dipisahkan dengan lingkungan social yang sering dihadapkan berbagai pokok permasalahan. Masa remaja ditandai dengan sejumlah karateristik penting yang meliputi pencapaian hubungan yang matang dengan teman sebaya, dapat menerima dan belajar peran sosial sebagai pria atau wanita dewasa yang dijunjung tinggi oleh masyarakat, menerima keadaan fisik dan mampu menggunakannya secara efektif, mencapai kemandirian emosional dari orang tua dan orang dewasa lainya, memilih dan mempersiapkan karier dimasa depan sesuai dengan minat dan kemampuanya.(Desmita) dalam Hidayat, 2016.

Siswa di sekolah harus mampu mengontrol diri dalam bertingkahlaku agar dapat mengembangkan potensi diri baik dalam aspek akademis maupun non akademis. Sirikulchayanonta (dalam Patty, 2016) menyatakan bahwa kontrol diri adalah kemampuan individu untuk mengambil tindakan, berpikir, dan berperilaku yang akan menhasilkan perbaikan diri. Menurut Ghufron (2017:23) kontrol diri diperlukan guna membantu individu dalam mengatasi kemampuanya yang terbatas dan mengatasi berbagai hal merugikan yang mungkin terjadi yang berasal dari luar. Siswa disekolah kadang kurang dapat mengontrol diri. Untuk mengembangkan kontrol diri siswa diberikan layanan bimbingan konseling.

Praktik bimbingan dan konseling merupakan satu kesatuan aktivitas yang tidak terpisahkan. Bimbingan dan konseling merupakan proses bantuan yang diberikan oleh pembimbing (konselor) kepada ndividu (konseli) melalui pertemuan tatap muka atau hubungan timbal balik antara keduanya, supaya konseli mempunyi kecakapan melihat serta menemukan masalahnya serta mempunyai kemampuan memecahkan masalah sendiri. Bimbingan dan konseling dapat dilaksanakan melalui berbagai jenis layanan. Layanan bimbingan dan konseling meliputi layanan dasar, layanan konseling kelompok, layanan bimbingan kelompok, layanan konseling inividu. Sukardi, Dewa Ketut (dalam Jannah, 2015) pelayanan bimbingan dan konseling bertujuan untuk membantu peserta didik agar dapat mencapai tujuan-tujuan perkembangan meliputi aspek pribadi, sosial, belajar dan karier.

Berdasarkan Peraturan Menteri Pendidikan dan Kebudayaan Republik Indonesia Nomor 111 tahun 2014 tentang bimbingan dan Konseling sesuai dengan pasal 2, layanan Bimbingan dan koseling pada satuan pendidikan memiliki fungsi sebagai pemahaman diri dan lingkungan, pertumbuhan dan dan perkembangan, penyesuaian diri dengan diri sendiri dan lingkungan, penyaluran pilihan pendidikan, pekerjaan, dan karir, pencegahan timbulnya masalah, perbaikan dan penyembuhan, pengembangan potensi optimal. Dan pasal 3 layanan bimbingan koseling memiliki tujuan membantu konseli mencapai perkembangan optimal dan kemandirian secara utuh dalam aspek pribadi, belajar, sosial, dan karir.

Peraturan menteri pendidikan dan kebudayaan republik Indonesia nomor 111 tahun 2014 tentang bimbingan dan konseling juga menjelaskan kegiatan dan alokasi waktu layanan, di dalamnya disebutkan adanya layanan bimbingan dan konseling di luar kelas yang meliputi konseling individual, koseling kelompok, bimbingan kelompok, kujungan rumah dan alih tangan kasus. Dari bimbingan dan konseling di luar kelas yang akan dibahas adalah bimbingan kelompok. Bimbingan kelompok merupakan pemberian bantuan kepada peserta didik/konseli melalui kelompok-kelompok kecil terdiri atas dua sampai sepuluh orang untuk pencegahan masalah, pemeliharaan nilai-nilai atau pengembangan ketrampilan hidup yang dibutuhkan. Bimbingan kelompok harus dirancang sesuai dengan kebutuhan nyata anggota kelompok. Topik bahasan dapat ditetapkan berdasarkan kesepakatan anggota kelompok atau dirumuskan oleh konselor atau guru bimbingan dan konseling berdasarkan pemahaman 
atau data tertentu. Pelaksanaan kegiatan layanan bimbingan dan konseling di luar kelas mempunyai perhitungan dan alokasi waktu sehingga peserta didik/konseli diharapkan bisa mencapai kemandirian dalam kehidupanya. Dari penjelasan di atas diharapkan masalah kontrol diri siswa dapat diatasi dengan menggunakan layanan bimbingan kelompok menggunakan teknik sosiodrama.

Layanan yang dapat diberikan salah satunya adalah layanan bimbingan kelompok. Bimbingan kelompok adalah layanan bmbingan yang diberikan dalam suasana kelompok (Prayitno, 2013 : 309). Bimbingan kelompok di sini yang dimaksudkan adalah untuk mencegah berkembangnya masalah atau kesulitan pada diri konseli (siswa) bimbingan kelompok dapat berupa penyampaian informasi atau aktivitas kelompok membahas masalah pendidikan, pekerjaan, pribadi dan masalah sosial. Dalam layana tersebut, para siswa dapat diajak bersama-sama mengemukakan pendapat tentang sesuatu dan membicarakan topiktopik penting.

Berdasarkan hasil observasi yang telah dilakukan di SMK Nusa Bangsa Demak ditemukan siswa yang berbicara kurang sopan kepada orang lain, saat pelajaran gaduh, mudah marah dan peragaulan kurang baik. Hal tersebut membuktikan bahwa kontrol diri siswa SMK Nusa Bangsa perlu mendapatkan perhatian dengan pertimbangan minimnya konselor di SMK Nusa Bangsa.

Teknik sosiodrama adalah permainan peran yang ditujukan untuk memecahkan masalah sosial yang timbul dalam hubungan antar manusia. (Romlah, 2001:104). Tenkik sosiodrama dapat dipandang tepat karena teknik ini bertujuan untuk memecahkan permasalahan berkaitan dengan hubungan sosial, kenakalan remaja, interaksi sosial, permasalahan latar belakang keluarga yang dilakukan secara kelompok. Mulyasa (dalam Hamid, 2018) juga mengemukakan bahwa dalam teknik sosiodrama siswa mempunyai kesempatan untuk menggali potensi belajar yang dimiliki melalui sebuah pemeranan tokoh tertentu kaitannya dalam permasalahan sosial.

Berdasarkan observasi tersebut maka teknik sosiodrama dirasa dapat membantu mengatasi permasalahan kontrol diri siswa. Sosiodrama adalah teknik untuk memecahkan masalah dalam format kelompok dengan memerankan suatu peranan tertentu dari situasi masalah sosial. Oleh sebab itu sosiodrama akan digunakan dalam layanan bimbingan kelompok untuk membantu siswa agar bisa mengontrol dirinya.

Dari hasil IKMS yang di bagikan kepada siswa-siswi kelas X SMK Nusa Bangsa Demak sebanyak 2 kelas, menunjukkan rata-rata permasalahan yang harus segera ditangani adalah masalah kontrol diri siswa. Beberapa permasalahan yang lain adalah kurang mampu mengendalikan diri, berpikir dan bersikap positif $47,1 \%$, ingin bisa meningkatkan ibadah keagamaan $50,0 \%$, sulit mematuhi tata tertib sekolah $55,9 \%$, sulit menyusun jadwal di sekolah dan di rumah70,6\%, sering kali tidak siap mengikut ujian $67,6 \%$, merasa menjadi anak paling bodoh dikelas $32,4 \%$. Dari data di atas maka peneliti akan melakukan dengan judul "Pengaruh Bimbingan Kelompok dengan Teknik Sosiodrama terhadap Kontrol Diri Siswa Kelas X SMK Nusa Bangsa Demak.

\section{Metode}

Penelitian ini menggunakan metode true experiment design dengan model pretestposttest control group design, dengan adanya pretest dan posttest untuk mengetahui keadaan awal dan akhir kelompok eksperimen dan kelompok kontrol. Penelitian ini dilaksanakan di SMK Nusa Bangsa Demak. alasan peneliti melakukan penelitian di SMK Nusa Bangsa Demak yaitu di SMK Nusa Bangsa Demak ditemukan permasalahan kontrol diri rendah. Pada siswa kelas $X$ penelitian dilaksanakan pada tanggal 10 Januari - 20 September 2019 pada sampel yang diambil secara rendom pada kelas $\mathrm{X}$ semester II tahun ajaran 2019/2020 dengan rincian menyusun proposal penelitian, penyusunan instrument penelitian, persiapan penelitian, melaksanakan penelitian ekperimen, menyusun hasil penelitian, dan penyempurnan. 
Populasi dalam penelitian ini adalah seluruh siswa kelas X SMK Nusa Bangsa Demak. dalam penelitian ini pengambilan sampel dilakukan dengan teknik sampling simple random sampling, yaitu pengambilan dilakukan secara rendom di dapatkan 20 siswa kelas $X$

Teknik pengumpulan data yang digunakan dalam penelitian ini skala kontrol diri digunakan untuk membandingkan skor sebelum mendapat perlakuan dengan setelah mendapat perlakuan mengalami peningkatan atau tidak.

Instrumen yang digunakan adalah sebuah skala psikologis, hasil uji coba dianalisis untuk mengetahui validitas, reliabilitas. Dari 30 item pernyataan terdapat 24 item pernyataan yang valid.

Analisis data yang dilakukan pada penelitian ini terdiri dari data awal dan data akhir. Analisis data awal dapat dilihat dari pretest sebelum diberi perlakuan menggunakan layanan bimbingan kelompok dengan teknik Sosiodrama sudah dinormalitaskan dengan menggunakan uji lilifors. Kemudian untuk mengetahui pengaruh layanan bimbingan kelompok dengan teknik sosiodrama digunakan hipotesis Uji t dan Uji-t.

\section{Hasil dan Pembahasan}

Perhitungan uji normalitas pada penelitian ini menggunakan uji lillifors dengan taraf signifikan $5 \%$. Kriteria dalam uji normalitas ini adalah jika $\mathrm{Lo}<\mathrm{L}_{\text {tabel }}$ maka data berdistribusi normal, sedangkan jika 0,125 0,258 pada kelompok eksperimen dan 0,217 0,258 maka data berdistribusi normal. Berikut rekapitulasi hasil perhitungan normalitas awal data sampel berikut.

Tabel 1. Uji Normalitas Data Awal (Pretest) Kemampuan Kontrol diri

\begin{tabular}{lccc}
\hline \multicolumn{1}{c}{ Kelas } & Lo & Ltabel & Kesimpulan \\
\hline Eksperimen & 0,125 & 0,258 & Berdistribusi normal \\
Kontrol & 0,217 & 0,258 & Berdistribusi normal \\
\hline
\end{tabular}

Berdasarkan Tabel 1 terlihat bahwa hasil perhitungan yang diperoleh dari nilai pretest, maka berdasarkan uji normalitas diperoleh $\mathrm{Lo}<\mathrm{L}_{\text {tabel }}$ yaitu 0,125 $<0,258$ pada kelompok eksperimen dan 0,217<0,258 pada kelompok kontrol pada signifikan $5 \%$ dengan $\mathrm{N}$ 10, maka Ho diterima, Sehingga dapat disimpulkan bahwa data pretest kemampuan kontrol diri berdistribusi normal.

\section{Data Akhir}

Perhitungan uji normalitas pada penelitian ini menggunakan uji lilifors dengan taraf signifikan $5 \%$. Kriteria uji normalitas ini adalah jika $L o<L_{\text {tabel }}$ maka data berdistribusi normal. Berikut rekapitulasi hasil perhitungan normalitas awal data sampel berikut :

Tabel 2. Uji Normalitas Data Akhir (Posttest) Kemampuan Kontrol Diri

\begin{tabular}{lccc}
\hline \multicolumn{1}{c}{ Kelas } & Lo & Ltabel & Kesimpulan \\
\hline Eksperimen & 0,227 & 0,258 & Berdistribusi normal \\
Kontrol & 0,245 & 0,258 & Berdistribusi normal \\
\hline
\end{tabular}

Berdasarkan Tabel 2 terlihat bahwa hasil perhitungan yang diperoleh dari skor posttest, maka berdasarkan uji normalitas diperoleh $\mathrm{Lo}<\mathrm{L}_{\text {tabel }}$ berdasarkan hasil post-test yaitu $0,227<0,258$ pada kelompok eksperimen dan 0,245 $<0,258$ pada kelompok kontrol pada signifikan 5\% dengan N 10, maka Ho diterima, Sehingga dapat disimpulkan bahwa data post-test kemampuan kontrol diri berdistribusi normal.

Uji hipotesis peneliti menggunakan yaitu Uji $t$ dengan teknik analisis $t$ tes untuk menguji nilai pretest diperoleh hasil $\mathrm{t}_{\text {hitung }} 0,39>\mathrm{t}_{\text {tabel }} 2,100$. Dapat disimpulkan bahwa tidak ada perbedaan kemampuan kontrol diri siswa antara kelompok eksperimen dan kelompok kontrol. 
Hipotesis kedua yaitu uji-t test yang bertujuan untuk mengetahui seberapa besar pengaruh antara rata-rata pretest dan rata-rata posttest. Dari hasil perhitungan uji t-test diperoleh hasil $t_{\text {hitung }} 3,62>t_{\text {tabel }}$ 2,100 maka Ho ditolak dan Ha diterima jadi dapat disimpulkan bahwa ada pengaruh layanan bimbingan kelompok dengan teknik sosiodrama untuk meningkatkan kontrol diri siswa kelas X SMK Nusa Bangsa Demak karena memiliki perbedaan yang signifikan dilihat dari hasil perhitungan uji t.

\section{Simpulan dan Saran}

Berdasarkan hasil analisis dan pembahasan hasil bahwa layanan bimbingan kelompok dengan teknik sosiodrama mengalami peningkatan terhadap kemampuan kontrol diri siswa kelas X SMK Nusa Bangsa Demak. hal ini dapat dilihat pada hasil pretest dan posttest pada kelompok kontrol dengan rata-rata pretest mengalami selisih peningkatan sebanyak 6,964\% sedang pada kelompok ekperimen yang diberikan layanan bimbingan kelompok dengan teknik sosiodrama mengalami selisih peningkatan sebanyak 20,492 \% sehingga dapat disimpulkan bahwa layanan bimbingan kelompok dengan teknik sosiodrama dapat meningkatkan kontrol diri siswa kelas X SMK Nusa Bagsa Demak.

\section{Daftar Pustaka}

Arikunto, Suharsimi. 2010. Prosedur Penelitian suatu Pendekatan Praktik. Jakarta: Rineka Cipta.

Aviyah, Avi \& M.Farid.2014. Religiusitas, Kontrol diri dan kenakalan remaja. Persona, Jurnal Psikologi Indonesia. (https://scholar.google.co.id/scholar?hl=id\&q=religiusitas\%2C+kontrol\%2C+\&btnG di unduh pada tanggal 2 April 2017).

Alwisol. 2004. Psikologi Kepribadian. Malang: UMM Malang.

Erlangga. 2018. "Bimbingan Kelompok Meningkatkan Ketrampilan Berkomunikasi Siswa" Jurnal. Jurnal ilmiah psikologi vol 4.

Fatimah, E. (2010).Psikologi Perkembangan.Bandung: CV Pustaka Setia.

Ghufron, M.Nur \& Risnawita, Rini. 2017. Teori-Teori Psikologi.Yogyakarta: Ar-ruzz Media.

Goleman, Daniel. 2005. Kecerdasan Emosi untuk Mencapai Puncak Prestasi. Jakarta: PT. Gramedia

Gunarsa, Y.Singgih D. 2004. Dari Anak Sampai Usia Lanjut. Jakarta: PT. BPK Gunung Mulia.

Hamid. 2018. "Penerapan teknik sosiodrama dalam bimbingan kelompok untuk meningkatkan ketrampilan komunikasi interpersonal siswa SMK NEGERI 8 Makasar" Jurnal. Jurnal mimbar kesejahteraan sosial vol 1.

Hamidah, Sochibatul Nur. 2017. Pengaruh Layanan Bimbingan Kelompok Teknik Penguatan Positif (Positive Reinforcement) Terhadap Pengendalian Diri Peserta Didik Kelas $X$ SMK PGRI 4 Kediri Tahun Pelajaran 2016/2017. Universitas Nusantara PGRI Kediri. Vol 1, No.04

Hidayat. 2016. "Konsep diri, Adversty Quotient dan Penyesuaian Diri Pada Remaja" Jurnal. Jurnal Psikologi Indonesia vol 5. 
Jannah. 2015. "Pelaksanaan layanan Bimbingn Kelompok dalam pemilihan kegiatan ekstrakurikuler di SMP NEGERI 1 Rantau” Jurnal. Jurnal Mahasiswa BK An-Nur vol 1.

Lubis. 2017. "Bimbingan Kelompok Dengan Teknik Sosiodrama Meningkatkan Regulasi Emosi Siswa SMA di Kota Bengkulu" Jurnal. Jurnal ilmiah Bimbingan dan Konseling vol 1.

Mukhtar, Yusuf Samsu, dan Budiamin Amin. 2016. Program Layanan Bimbingan Klasikal untuk Meningkatkan Self-Control Siswa. Psikopedagogia Vol 5, No 1.Diunduh pada tanggal 05 April pukul 18.25 WIB.

Nurhaini. 2018. "Pengaruh Konsep Diri dan Kontrol Diri Dengan Perilaku Konsumtif Terhadap Gadget Remaja SMAN 1 Tanah Grogot" Jurnal. Psikoborneo vol 6. Puspahayati, J. Q.2014. Self-Control Remaja Yang Mengikuti Karate dengan. Yang Tidak Mengikuti Karate. Ejournal: Universitas Muhammdiyah Malang Fakultas Psikologi. (http://ejournal.umm.ac.id/di unduh pada tanggal 4 Juni 2015).

Nurihsan, Juntika Achmad.2005. Strategi Layanan Bimbingan dan Konseling. Bandung: PT Refika Aditama

Patty. 2016. "Hubungan dukungan sosial teman sebaya, Kontrol diri, dan jenis kelamin dengan prestasi belajar siswa di SMA Kristen YPKPM Ambon" Jurnal. Psikodimensia vol 15

Prayitno. 2013. Dasar-dasar Bimbingan dan Konseling (cet ke-3). Jakarta: Ghalia Indonesia.

Puspahayati, J. Q.2014. Self-Control Remaja Yang Mengikuti Karate dengan Yang Tidak Mengikuti Karate. Ejournal: Universitas Muhammdiyah Malang Fakultas Psikologi. (http://ejournal.umm.ac.id/di unduh pada tanggal 4 Juni 2015).

Romlah, T. 2001. Teori dan praktek Bimbingan kelompok. Malang: UNM.

Rusmana, Nandang. 2009. Bimbingan Dan Konseling Di Sekolah. Bandung : Rizqi Press.

Soegeng. 2015. Dasar-dasar Penelitian. Yogyakarta : Magnum Pustaka Utama.

Sugiyono. 2017. Metode Penelitian Kuantitatif Kualitatif dan R\&D. Bandung: Alfabeta.

Sugiyono. 2009. Metode Penelitian Pendidikan. Bandung: Alfabeta.

Sudjana. 2005. Metoda Statistika. Bandung: PT Tarsito.

Sukardi, Dewa Ketut. 2008. Pengantar Pelaksanaan Program Bimbingan dan Konseling di Sekolah. Jakarta: PT. Rineka Cipta.

Sukarno, Anton dan Venty. 2015. Statistik Pendidikan: Universitas PGRI Semarang.

Sutoyo Anwar. 2009. Pemahaman Individu. Semarang : Universitas Negeri Semarang.

Titisari. 2017. "Hubungan Antara Penyesuaian diri dan Kntrol diri dengan Perilaku Delikuen pada siswa SMA Muhamadiyah 1, Jombang” Jurnal. Psikodimensia vol 16.

Widyastuti. 2017. "Evalusi Layanan Bimbingan Kelompok di Sekolah Menengah Pertama Brdasarkan Model Kesenjangan” Jurnal. Jurnal Konseling GUSIJANG vol 3. 
Winarlin. 2016. Efektivitas Teknik Sosiodrama Melalui Bimbingan Kelompok Untuk Mengurangi Perilaku Agresif Verbal Siswa SMP" Jurnal. Jurnal kajian bimbingan dan konseling vol 1.

Zuhara. "Efektivitas Teknik Sosiodrama Untuk Meningkatkan Komunikasi Interpersonal Siswa" Jurnal. Jurnal IImiah Edukasi vol 1. 